\title{
Vascular Smooth Muscle Cells Contribute to Atherosclerosis Immunity
}

\author{
Desheng $\mathrm{Hu}^{1,2 *}$, Changjun $\mathrm{Yin}^{3}$, Shanshan Luo ${ }^{2}$, Andreas J. R. Habenicht ${ }^{3}$ and \\ Sarajo K. Mohanta ${ }^{3 *}$
}

${ }^{1}$ Department of Integrated Traditional Chinese and Western Medicine, Union Hospital, Tongji Medical College, Huazhong University of Science and Technology, Wuhan, China, ${ }^{2}$ Institute of Hematology, Union Hospital, Tongji Medical College, Huazhong University of Science and Technology, Wuhan, China, ${ }^{3}$ Institute for Cardiovascular Prevention,

Ludwig-Maximilians-University Munich, Munich, Germany

OPEN ACCESS

Edited by:

Teruki Dainichi,

Kyoto University, Japan

Reviewed by:

Gianluca Grassia,

University of Glasgow,

United Kingdom

Coleen McNamara,

University of Virginia, United States

*Correspondence:

Desheng Hu

desheng.hu@hust.edu.cn

Sarajo K. Mohanta

sarajo.mohanta@

med.uni-muenchen.de

Specialty section:

This article was submitted to

Immunological Tolerance and

Regulation,

a section of the journal

Frontiers in Immunology

Received: 10 January 2019 Accepted: 30 April 2019

Published: 17 May 2019

Citation:

Hu D, Yin C, Luo S, Habenicht AJR and Mohanta SK (2019) Vascular

Smooth Muscle Cells Contribute to Atherosclerosis Immunity.

Front. Immunol. 10:1101

doi: 10.3389/fimmu.2019.01101
Vascular smooth muscle cells (VSMCs) constitute the major cells in the media layer of arteries, and are critical to maintain the integrity of the arterial wall. They participate in arterial wall remodeling, and play important roles in atherosclerosis throughout all stages of the disease. Studies demonstrate that VSMCs can adopt numerous phenotypes depending on inputs from endothelial cells (ECs) of the intima, resident cells of the adventitia, circulating immune cells, hormones, and plasma lipoproteins. This plasticity allows them to perform multiple tasks in physiology and disease. In this minireview, we focus on a previously underappreciated activity of VSMCs, i.e., their impact on atherosclerosis immunity via formation of artery tertiary lymphoid organs (ATLOs).

Keywords: atherosclerosis, vascular smooth muscle cells, endothelial cells, intima, adventitia, artery tertiary lymphoid organs

\section{PLASTICITY OF VSMCs IN PHYSIOLOGY AND DISEASE}

Vascular smooth muscle cells (VSMCs) are the major constituents of medium- and large-sized arteries. Although mechanisms of atherogenesis largely remain to be defined, studies have demonstrated that disease progression involves crosstalk between immune cells with both ECs and VSMCs. Some of these interactions promote plaque growth while others attenuate the size, cellular composition, and stability of atherosclerotic plaques $(1,2)$ (Figure 1, Table 1). VSMCs show remarkable plasticity in response to vascular injury, inflammation, and lipoprotein accumulation during disease progression via reprogramming gene expression and a shift to a proliferative, pro-migratory, and activated phenotype, i.e., phenotype switching (5). In Figure 1, we depict critical molecular switches that have been proposed to be important regulators of disease progression $(3,6,8,11)$. During atherosclerosis initiation, blood-derived monocytes, which have been recruited into the intima, accumulate lipid giving them a foamy appearance. These foam cells contribute to fatty streak formation which constitutes the earliest and possibly reversible stage of atherosclerotic plaques. Fatty streaks gradually develop into atheromas/plaques ultimately leading to expanded plaques that contain VSMCs, $\mathrm{T}$ cells and myeloid cells (Figure 1) (33). Intriguingly, the composition of an atherosclerotic plaque rather than its size determines its stability as fibrous cap thickness and necrotic core size are potential hallmarks of a stable vs. an unstable plaque, respectively $(4,9)$. VSMCs in the intima layer are traditionally viewed as beneficial during atherogenesis because they produce extracellular matrix components, thereby promoting formation of stronger fibrous caps resulting in protection against plaque rupture $(4,9)$. It is increasingly apparent that 


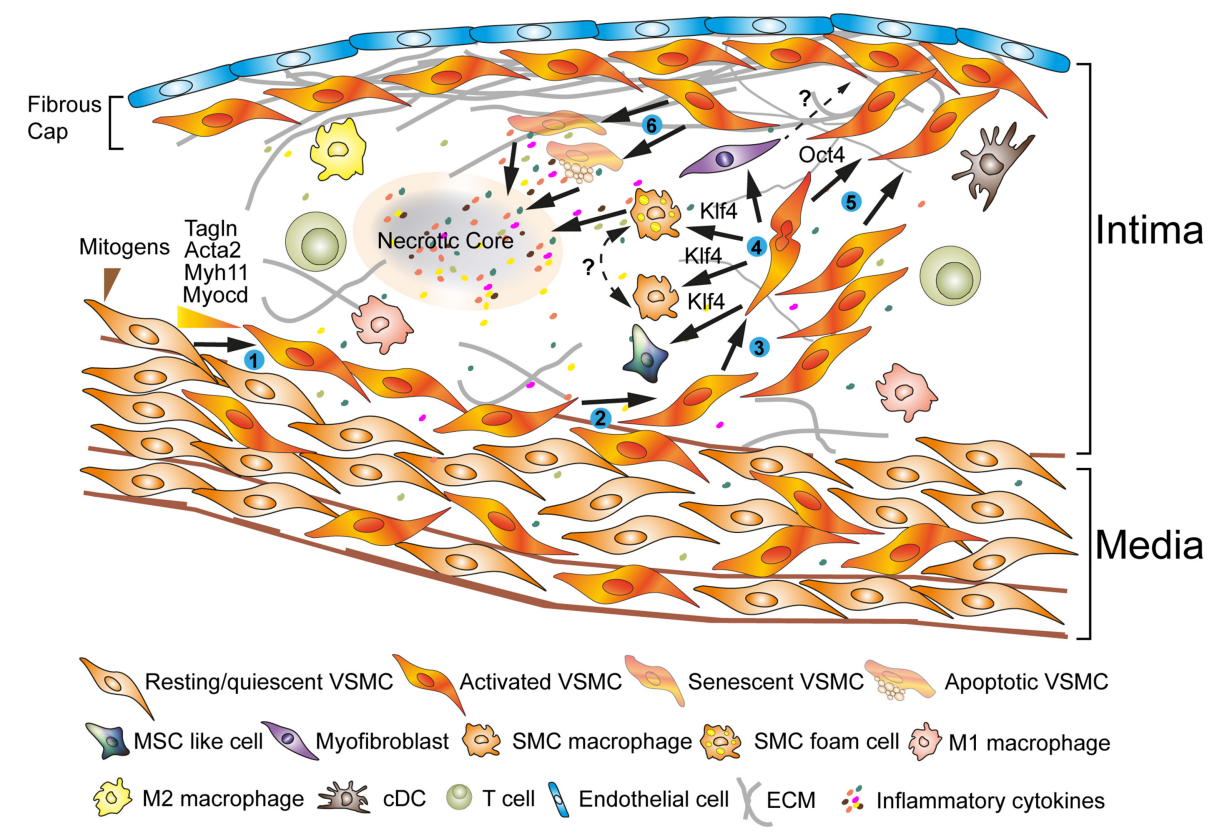

FIGURE 1 | Phenotypes of VSMCs during atherosclerosis progression reveal extraordinary plasticity. ECs and VSMCs in atherosclerotic plaques show activated phenotypes $(\mathbf{0})(3,4)$. Some of the VSMCs originate in the media following recruitment into the intima; other VSMCs may be bone marrow-derived or they may originate from myeloid cells in the circulation (0) (3). A fraction of VSMCs proliferate (8) $(3,5)$. VSMCs secrete extracellular matrix components; the pluripotent transcription factor, i.e., Klf4, may play major roles in a process referred to as phenotype switching $(\mathbf{(})(6,7)$. In attempts to shield the atherosclerotic plaque from lethal rupture, Oct4 may control a process that has been termed remigration to form a fibrous cap (⿶) $(4,8-10)$. Senescence and apoptosis trigger the generation of additional inflammatory cytokines to form a necrotic core initiating a vicious cycle with lethal clinical consequences during the late stages of the disease $(\mathbf{6})(3,4,11)$.

VSMCs undergo a plethora of structural and functional phenotypical transformations and may even completely lose their native features to acquire characteristics of other cell types including macrophages. Data indicate that VSMCs can acquire dichotomic phenotypes with a Janus head-type nature, i.e., pro- vs. anti-atherogenic properties, depending on the tissue environment and action of risk factors (3). VSMCs release cytokines to stimulate adjacent ECs to express adhesion molecules and release cytokines, and/or enhance chemotaxis of monocyte/macrophages into the plaque $(3,34,35)$ (Table 1). These data indicate that accumulation of VSMCs in the fibrous cap or intima are beneficial, whereas their loss or transition into an inflammatory phenotype are detrimental, and that the balance between VSMCs proliferation/migration vs. death/senescence determines atheroprogression vs. plaque stability (3). Various additional aspects of VSMC biology in health and disease were recently covered by a series of excellent reviews (https:// academic.oup.com/cardiovascres/issue/114/4) and will not be covered here. Below, we therefore focus attention on the role of the adventitia and the potential impact of VSMCs in ATLO formation.

\section{VSMCs AFFECT ADVENTITIA IMMUNE RESPONSES IN HYPERLIPIDEMIC MICE}

During the last two decades, it became increasingly apparent that the adventitia is a highly complex and immunologically active tissue harboring cells as diverse as stromal cells, nerves, lymph vessels, vasa vasora, and resident leukocytes/progenitor cells all of which have the ability to affect disease progress $(36,37)$. We observed that the adventitia of $A p o E^{-/-}$mice undergoes major restructuring events during all stages of atherosclerosis: Both innate and adaptive immune cells accumulate adjacent to the neighboring atherosclerotic plaques (Figure 2). Moreover, our studies in experimental mice were corroborated in human diseased arteries: We and others observed ATLO-like structures in the adventitia of patients presenting with atherosclerotic aortic aneurysms $(38,39)$ and more recently, Akhavanpoor et al. observed well-developed ATLOs in the adventitia of a considerable percentage of patients afflicted with ischemic heart disease (40). In murine atherosclerosis, lymph vessel-, high endothelial venule (HEV)-, and blood vessel neogenesis are prominent features of this restructuring process $(16,41)$.

\section{AGING OR CHRONICITY OR BOTH?}

Importantly, aging was found to be a major determinant of adventitia restructuring and sculpting. Fully developed ATLOs form during advanced stages of atherosclerosis but their early stages, i.e., T/B cell aggregates, emerge in parallel to the formation of atherosclerotic plaques (16, 27, 41, 42). Indeed, these early ATLOs form at the age of $\sim 30$ weeks and reach more advanced stages at around 52 weeks to peak at 78 weeks $(16,41)$. Similar age-dependent developmental stages of TLOs have been observed 


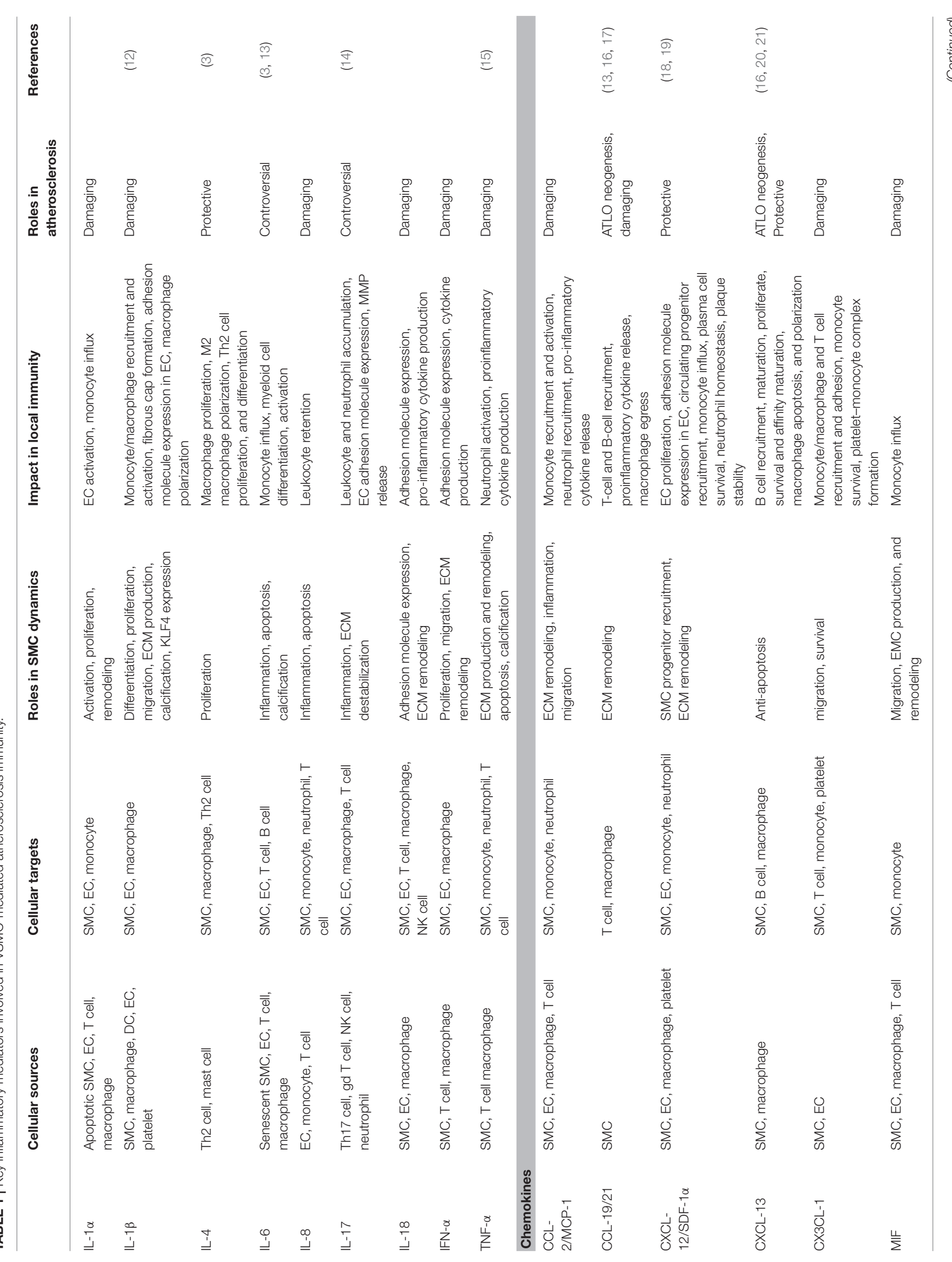




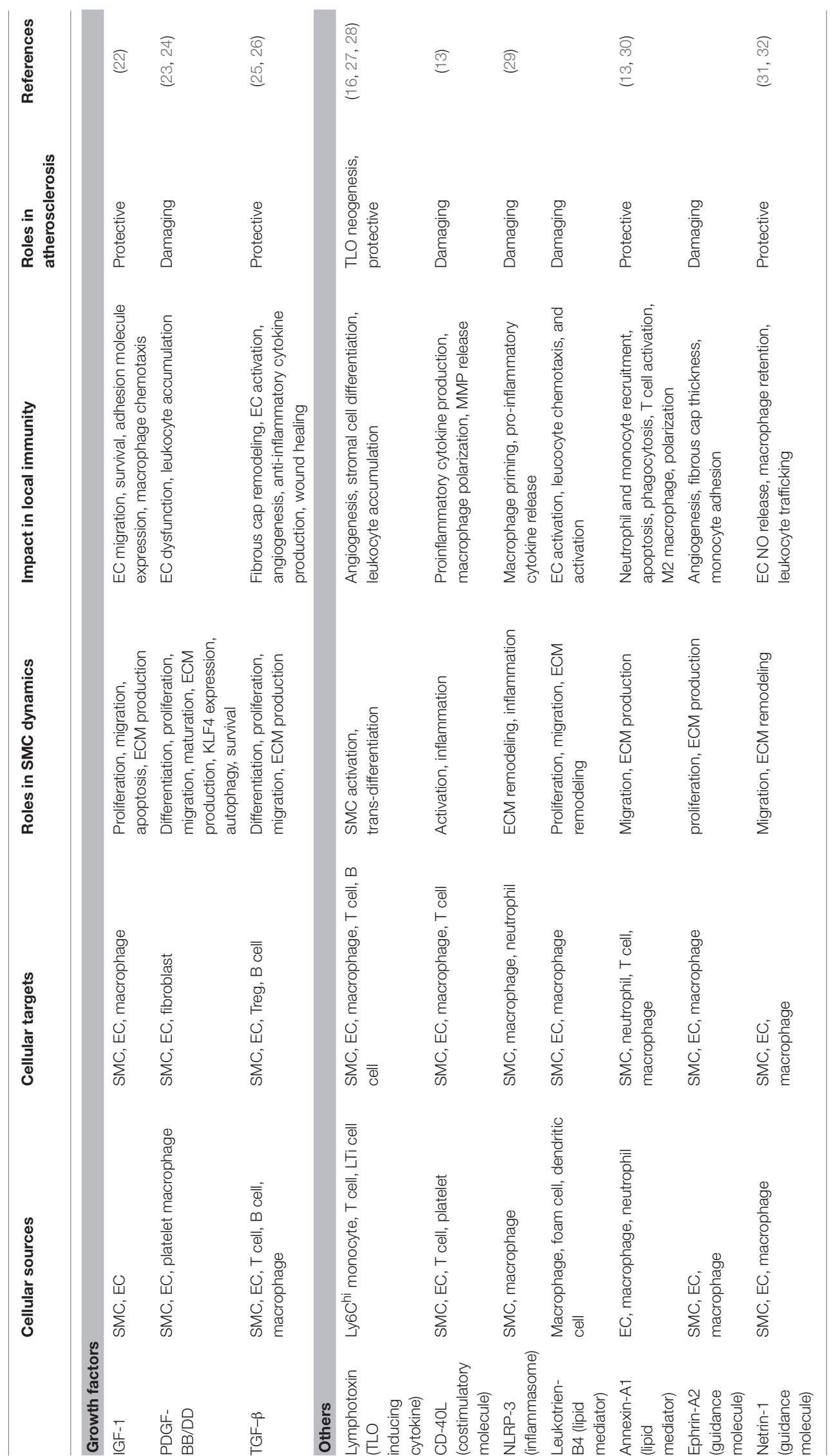




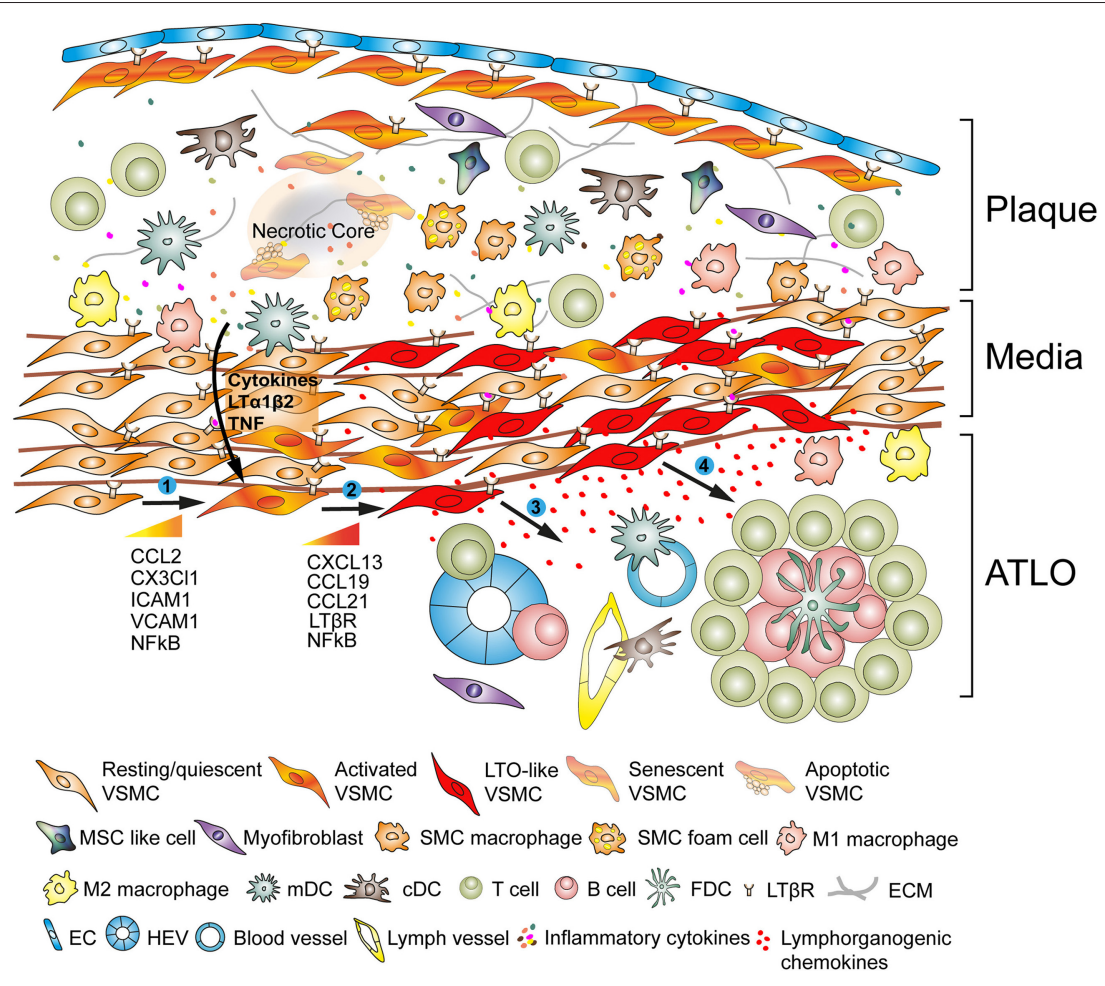

FIGURE 2 | Vascular smooth muscle cells (VSMC) participate in adventitia immunity during plaque formation. VSMCs sandwiched between atherosclerotic plaques and the adventitia adopt a lymphoid tissue organizer-like phenotype following activation via plaque-derived cues $(\mathbf{0})$ and subsequently transdifferentiate into LTo-like cells (2). By means of their proliferative and cytokine-expressing phenotype they affect the restructuring and sculpting of the adventitia including angiogenesis, HEV formation, and lymph vessel neogenesis (8). Phenotype switching also results in the expression and secretion of lymphorganogenic chemokines, i.e., CXCL13 and CCL21, thereby promoting ATLO formation depicted schematically in the lower part of the graph $(\mathbf{(})$.

in other chronic unresolvable diseases $(1,42)$. These data indicate that ATLO development is age-dependent and aging is positively associated with adventitial sculpting (Figure 2). However, the relation between aging and chronicity is difficult to study in murine atherosclerosis as atherosclerotic plaque development begins in the aortic arch, then travels sown the aorta to reach the abdominal aorta at later disease stages thus taking extended periods of time. More work is needed to clarify the important issue whether immune cell and/or VSMC senescence contributes to ATLO formation and which cells types, i.e., VSMCs, ECs, and/or immune cells are involved. Studies in other forms of TLO formation such as those occurring in the lung and the gastrointestinal tract would indicate that it is the chronicity of a persistent inflammatory tissue reaction rather than bona fide aging events of the immune system that is crucially contributing to the formation of ATLOs $(43,44)$.

\section{NEWLY FORMED ADVENTITIA STRUCTURES PARTICIPATE IN ATLO FUNCTION BY PROMOTING LYMPHOCYTE RECIRCULATION}

Advanced ATLO stages include T/B cell aggregates, germinal centers within activated B cell follicles, lymph vessels, HEVs in $\mathrm{T}$ cell areas, and extracellular conduit meshworks (16). These major changes resemble structures reminiscent of those found in secondary lymphoid organs where they promote fundamental aspects of immune responses toward antigen including recirculation of naïve lymphocytes to find their cognitive antigens/autoantigens, and organizing affinity maturation of $\mathrm{B}$ cells toward potential autoantigens. Using adoptive lymphocyte transfer studies, we observed that ATLOs greatly enhance lymphocyte recruitment into the arterial wall by both promoting immigration and concomitant attenuation of emigration of antigen-inexperienced lymphocytes (27). Subsequent to their recruitment, $\mathrm{T}$ cells become activated, begin to proliferate, and some of the $\mathrm{CD} 4 \mathrm{~T}$ helper cells are converted into induced $\mathrm{T}$ regulatory cells. These data reveal that the immune system in the adventitia is highly responsive toward the underlying inflammatory tissue reaction of the arterial wall. Moreover, B cells which form germinal centers in activated B cell follicles appear to undergo a germinal center reaction in the presence of follicular dendritic cells where some are converted into memory $\mathrm{B}$ cells while others leave the germinal centers to become plasma cells (45). When taken together, these data indicate that ATLOs rather than secondary lymphoid organs (as previously thought) organize atherosclerosis immunity. 


\section{ATLO FORMATION IS HIGHLY TERRITORIALIZED INDICATING THAT SIGNALS ARE TRANSMITTED FROM PLAQUES TO THE ADVENTITIA VIA LYMPHOID TISSUE ORGANIZER-LIKE VSMCs}

Another aspect of adventitia restructuring during atherogenesis is that ATLO formation is highly territorialized being largely restricted to adventitia segments adjacent to atherosclerotic plaques in the abdominal aorta in mice $(16,45)$. ATLOs are only occasionally found in the adventitia of the innominate artery or of the aortic arch where atherosclerosis is most prominent. Immune cells in the thoracic segments of the aorta are mainly composed of $\mathrm{T}$ cell aggregates compared to ATLOs in the abdominal aorta $(16,41)$. The exact mechanism for territoriality of ATLOs formation in the abdominal aorta is still unknown. TLOs appear to be a feature of many chronic unresolvable inflammatory diseases and are prominent hallmarks of autoimmune diseases (42). The cellularity and structures of TLOs in atherosclerosis are similar to TLOs in many other chronic diseases including cancer-associated TLO formation $(46,47)$. The field of TLO biology has dramatically expanded in recent years raising the important possibility that new therapeutic target may be identified via understanding of TLO's function in each of TLO-associated diseases. However, the various types of TLOs reveal some disease-specific features, which may ultimately determine whether the associated immune responses are harmful or protective. Such disease-specific characteristics possibly arise through one of several mechanisms including organ specificity and the nature of tissue damage $(1,42)$. The development of lymphoid organs is a complex process which involves hematopoietic lymphoid tissue inducer (LTi) cells, non-hematopoietic stromal lymphoid tissue organizer (LTo) cells and LT $\beta$ R signaling. Our in-vitro studies of mouse aorta VSMCs indicated that upon appropriate stimulation they can serve as LTo-like cells (20), originally identified during embryonic development during the formation of secondary lymphoid tissues including lymph nodes and spleen $(48,49)$ (see below). It is important to note that ATLOs appear to involve VSMCs as important participants whereas other TLOs involve other LTo-like mesenchymal cells (50). The common denominator of all forms of TLOs, however, appears to beunlike secondary lymphoid organs-a chronic inflammatory tissue reaction which drives the immune system to form these lymphoid structures close to or in some instances within the diseased tissue $(42,43)$.

\section{VSMCs DIRECTLY CONTRIBUTE TO ADVENTITIA IMMUNITY IN ATHEROSCLEROSIS}

In view of the highly territorialized nature of ATLOs adjacent to atherosclerotic plaques, we reasoned that VSMCs may be involved in ATLO formation and by the same token may adopt a functional role in atherosclerosis progression. VSMCs highly express the LT $\beta R$ constitutively (16), whereas its ligand $\mathrm{LT} \alpha_{1} \beta_{2}$ is expressed on various immune cells termed LTi cells (51). VSMCs are hypothesized to be activated through the LT $\beta$ R-LT signaling pathway by LTi cells involved in secondary lymphoid tissue neogenesis. The origin of LTi cell has not yet been clearly determined though activated macrophages and other immune cells in the intima plaque are candidates for this activity in LTO neogenesis. In response to cellular and soluble mediators VSMCs appear to undergo a distinct type of phenotype switching to a LTo-like phenotype by paracrine secretion of the lymphorganogenic chemokines, i.e., CXCL13 and CCL21, thereby attracting immune cells, e.g., macrophages/dendritic cells, $\mathrm{T}$ cells, and $\mathrm{B}$ cells to the local adventitia milieu leading to formation of ATLO in the adventitia $(27,41,45)$ (Table 1). Global or VSMC-specific deficiency of LT $\beta R$ in aged hyperlipidemic $A p o E^{-/-}$mice demonstrated increased atherosclerotic plaque formation indicating that the VSMC LT $\beta R$ has the ability to attenuate development of atherosclerosis under some experimental conditions (27). Other studies, however, showed that young global $A p o E^{-/-} L_{T b R^{-/-}}$mice maintained under a high fat diet (HFD) revealed a lower aortic plaque burden than their normal diet-fed $A p o E^{-/-}$counterparts (52). These apparent contradictory data indicate that the roles of LT $\beta R$ in young mice and under conditions of excessive hyperlipidemia may be different in the two models. Alternatively, the high fat diet which leads to dramatic and possibly intoxicating levels of plasma lipids, may be responsible for these differences. Since we do not regularly use a high fat diet in $\mathrm{ApoE}^{-/-}$mice, these discrepancies remain unresolved issues though it has been shown that the immune system may be overwhelmed by extreme levels of plasma lipids [reviewed in Mohanta et al.(42)]. These data call for further studies to examine the molecular basis for the apparent dichotomy of the LT $\beta \mathrm{R}$ in atherosclerosis progression in young vs. aged mice and/or early vs. advanced atherosclerosis. In addition, bone marrow-derived macrophages may function as LT $\beta$ R-independent LTi cells and trigger the expression of CCL19, CCL20, and CXCL16 by VSMCs (53) (Table 1). Thus, VSMCs may participate in the formation of TLOs in atherosclerosis by upregulation of lymphorganogenic chemokines to promote immune cell aggregates in the adventitia. As mentioned above, ATLOs are common in humans burdened by ischemic coronary heart disease (40) and in human atherosclerotic aortic aneurysms $(38,39)$. When taken together, the occurrence of ATLOs in experimental mice and in human atherosclerosis raise important questions regarding the nature of atherosclerosis as an autoimmune disease: it is conceivable that during atherogenesis autoimmune $\mathrm{T}$ cells and autoimmune $\mathrm{B}$ cells directed against yet to be identified autoantigens are generated. Isolation of such autoimmune lymphocytes including sequencing of their $\mathrm{T}$ cell receptors and/or B cell receptors would allow to test major hypotheses in atherosclerosis. Indeed, atherosclerosis research would undergo a major shift and testing of individual autoimmune lymphocyte clones in functional in vitro and in vivo systems would become possible. 


\section{CONCLUSION}

Atherosclerosis is an inflammatory disease of arteries. VSMCs communicate with both the ECs and immune cells in the atherosclerotic plaques and resident cells in the adventitia. This ability allows VSMCs to affect atherosclerosis immunity in major ways including the formation of ATLOs. Further work is required to delineate the role of VSMCs during different stages of atherosclerosis, determine their role in young vs. aging arteries, and elucidate further their dichotomic roles in disease progression. A better understanding of these processes may open the way to develop therapeutic strategies for future intervention in clinically important late-stages of the disease.

\section{REFERENCES}

1. Yin C, Mohanta SK, Srikakulapu P, Weber C, Habenicht AJ. Artery tertiary lymphoid organs: powerhouses of atherosclerosis immunity. Front Immunol. (2016) 7:387. doi: 10.3389/fimmu.2016.00387

2. Libby P, Lichtman AH, Hansson GK. Immune effector mechanisms implicated in atherosclerosis: from mice to humans. Immunity. (2013) 38:1092-104. doi: 10.1016/j.immuni.2013.06.009

3. Bennett MR, Sinha S, Owens GK. Vascular smooth muscle cells in atherosclerosis. Circ Res. (2016) 118:692-702. doi: 10.1161/CIRCRESAHA. 115.306361

4. Clarke MC, Figg N, Maguire JJ, Davenport AP, Goddard M, Littlewood TD et al. Apoptosis of vascular smooth muscle cells induces features of plaque vulnerability in atherosclerosis. Nat Med. (2006) 12:1075-80. doi: $10.1038 / \mathrm{nm} 1459$

5. Owens GK, Kumar MS, Wamhoff BR. Molecular regulation of vascular smooth muscle cell differentiation in development and disease. Physiol Rev. (2004) 84:767-801. doi: 10.1152/physrev.00041.2003

6. Shankman LS, Gomez D, Cherepanova OA, Salmon M, Alencar GF, Haskins RM, et al. KLF4-dependent phenotypic modulation of smooth muscle cells has a key role in atherosclerotic plaque pathogenesis. Nat Med. (2015) 21:628-37. doi: $10.1038 / \mathrm{nm} .3866$

7. Gomez D, Owens GK. Smooth muscle cell phenotypic switching in atherosclerosis. Cardiovasc Res. (2012) 95:156-64. doi: 10.1093/cvr/cvs115

8. Cherepanova OA, Gomez D, Shankman LS, Swiatlowska P, Williams J, Sarmento OF, et al. Activation of the pluripotency factor OCT4 in smooth muscle cells is atheroprotective. Nat Med. (2016) 22:657-65. doi: 10.1038/nm.4109

9. Virmani R, Burke AP, Farb A, Kolodgie FD. Pathology of the vulnerable plaque. J Am Coll Cardiol. (2006) 47:C13-8. doi: 10.1016/j.jacc.2005.10.065

10. Yla-Herttuala S, Bentzon JF, Daemen M, Falk E, Garcia-Garcia HM, Herrmann J, et al. Stabilisation of atherosclerotic plaques. Position paper of the European Society of Cardiology (ESC) Working Group on atherosclerosis and vascular biology. Thromb Haemost. (2011) 106:1-19. doi: 10.1160/TH10-12-0784

11. Grootaert MOJ, Moulis M, Roth L, Martinet W, Vindis C, Bennett MR, et al. Vascular smooth muscle cell death, autophagy and senescence in atherosclerosis. Cardiovasc Res. (2018) 114:622-34. doi: 10.1093/cvr/cvy007

12. Gomez D, Baylis RA, Durgin BG, Newman AAC, Alencar GF, Mahan S, et al. Interleukin-1beta has atheroprotective effects in advanced atherosclerotic lesions of mice. Nat Med. (2018) 24:1418-29. doi: 10.1038/s41591-018-0124-5

13. Back M, Weber C, Lutgens E. Regulation of atherosclerotic plaque inflammation. J Intern Med. (2015) 278:462-82. doi: 10.1111/joim.12367

14. Akhavanpoor M, Akhavanpoor H, Gleissner CA, Wangler S, Doesch AO, Katus HA, et al. The Two Faces of Interleukin-17A in Atherosclerosis. Curr Drug Targets. (2017) 18:863-73. doi: 10.2174/1389450117666161229142155

15. Jia G, Cheng G, Gangahar DM, Agrawal DK. Insulin-like growth factor-1 and TNF-alpha regulate autophagy through c-jun $\mathrm{N}$-terminal kinase and Akt

\section{AUTHOR CONTRIBUTIONS}

All authors contributed to the design, writing, and editing of the submitted manuscript, and approved it for publication.

\section{FUNDING}

This work was funded by the National Natural Science Foundation of China (No. 31770983) to DH and (No. 81601747) to SL; German Research Council: YI 133/2-1 to CY; MO 3054/1-1 to SM; HA 1083/15-4 to AH; and European Research Area-Cardiovascular Disease (No. 01KL1808) to AH.

pathways in human atherosclerotic vascular smooth cells. Immunol Cell Biol. (2006) 84:448-54. doi: 10.1111/j.1440-1711.2006.01454.x

16. Grabner R, Lotzer K, Dopping S, Hildner M, Radke D, Beer M, et al. Lymphotoxin beta receptor signaling promotes tertiary lymphoid organogenesis in the aorta adventitia of aged $\mathrm{ApoE}^{-/-}$mice. J Exp Med. (2009) 206:233-48. doi: 10.1084/jem.20080752

17. Damas JK, Smith C, Oie E, Fevang B, Halvorsen B, Waehre T, et al. Enhanced expression of the homeostatic chemokines CCL19 and CCL21 in clinical and experimental atherosclerosis: possible pathogenic role in plaque destabilization. Arterioscler Thromb Vasc Biol. (2007) 27:614-20. doi: 10.1161/01.ATV.0000255581.38523.7c

18. Doring Y, Noels H, van der Vorst EPC, Neideck C, Egea V, Drechsler M, et al. Vascular CXCR4 limits atherosclerosis by maintaining arterial integrity: evidence from mouse and human studies. Circulation. (2017) 136:388-403. doi: 10.1161/CIRCULATIONAHA.117.027646

19. Akhtar S, Gremse F, Kiessling F, Weber C, Schober A. CXCL12 promotes the stabilization of atherosclerotic lesions mediated by smooth muscle progenitor cells in Apoe-deficient mice. Arterioscler Thromb Vasc Biol. (2013) 33:679-86. doi: 10.1161/ATVBAHA.112.301162

20. Lotzer K, Dopping S, Connert S, Grabner R, Spanbroek R, Lemser B, et al. Mouse aorta smooth muscle cells differentiate into lymphoid tissue organizerlike cells on combined tumor necrosis factor receptor-1/lymphotoxin betareceptor NF-kappaB signaling. Arterioscler Thromb Vasc Biol. (2010) 30:395402. doi: 10.1161/ATVBAHA.109.191395

21. Smedbakken LM, Halvorsen B, Daissormont I, Ranheim T, Michelsen AE, Skjelland M, et al. Increased levels of the homeostatic chemokine CXCL13 in human atherosclerosis-potential role in plaque stabilization. Atherosclerosis. (2012) 224:266-73. doi: 10.1016/j.atherosclerosis.2012.06.071

22. Higashi Y, Sukhanov S, Shai SY, Danchuk S, Tang R, Snarski P, et al. Insulin-like growth factor-1 receptor deficiency in macrophages accelerates atherosclerosis and induces an unstable plaque phenotype in apolipoprotein E-deficient mice. Circulation. (2016) 133:2263-78. doi: 10.1161/CIRCULATIONAHA.116.021805

23. Alexander MR, Owens GK. Epigenetic control of smooth muscle cell differentiation and phenotypic switching in vascular development and disease. Annu Rev Physiol. (2012) 74:13-40. doi: 10.1146/annurev-physiol-012110-142315

24. He C, Medley SC, Hu T, Hinsdale ME, Lupu F, Virmani R, et al. PDGFRbeta signalling regulates local inflammation and synergizes with hypercholesterolaemia to promote atherosclerosis. Nat Commun. (2015) 6:7770. doi: 10.1038/ncomms 8770

25. Low EL, Baker AH, Bradshaw AC. TGFbeta, smooth muscle cells and coronary artery disease: a review. Cell Signal. (2019) 53:90-101. doi: 10.1016/j.cellsig.2018.09.004

26. Da Ros F, Carnevale R, Cifelli G, Bizzotto D, Casaburo M, Perrotta M, et al. Targeting Interleukin-1beta Protects from Aortic Aneurysms Induced by Disrupted Transforming Growth Factor beta Signaling. Immunity. (2017) 47:959-73 e9. doi: 10.1016/j.immuni.2017.10.016 
27. Hu D, Mohanta SK, Yin C, Peng L, Ma Z, Srikakulapu P, et al. Artery tertiary lymphoid organs control aorta immunity and protect against atherosclerosis via vascular smooth muscle cell lymphotoxin beta receptors. Immunity. (2015) 42:1100-15. doi: 10.1016/j.immuni.2015.05.015

28. Ruddle NH. Lymphotoxin and TNF: how it all began-a tribute to the travelers. Cytokine Growth Factor Rev. (2014) 25:83-9. doi: 10.1016/j.cytogfr.2014.02.001

29. Paramel Varghese G, Folkersen L, Strawbridge RJ, Halvorsen B, Yndestad A, Ranheim T, et al. NLRP3 inflammasome expression and activation in human atherosclerosis. J Am Heart Assoc. (2016) 5:e003031. doi: 10.1161/JAHA.115.003031

30. de Jong RJ, Paulin N, Lemnitzer P, Viola JR, Winter C, Ferraro B, et al. Protective aptitude of annexin A1 in arterial neointima formation in atherosclerosis-prone mice-brief report. Arterioscler Thromb Vasc Biol. (2017) 37:312-5. doi: 10.1161/ATVBAHA.116.308744

31. Finney AC, Orr AW. Guidance molecules in vascular smooth muscle. Front Physiol. (2018) 9:1311. doi: 10.3389/fphys.2018.01311

32. van Gils JM, Derby MC, Fernandes LR, Ramkhelawon B, Ray TD, Rayner KJ, et al. The neuroimmune guidance cue netrin-1 promotes atherosclerosis by inhibiting the emigration of macrophages from plaques. Nat Immunol. (2012) 13:136-43. doi: 10.1038/ni.2205

33. Libby P, Ridker PM, Maseri A. Inflammation and atherosclerosis. Circulation. (2002) 105:1135-43. doi: 10.1161/hc0902.104353

34. Rodier F, Campisi J. Four faces of cellular senescence. J Cell Biol. (2011) 192:547-56. doi: 10.1083/jcb.201009094

35. Tchkonia T, Zhu Y, van Deursen J, Campisi J, Kirkland JL. Cellular senescence and the senescent secretory phenotype: therapeutic opportunities. J Clin Invest. (2013) 123:966-72. doi: 10.1172/JCI64098

36. Stenmark KR, Yeager ME, El Kasmi KC, Nozik-Grayck E, Gerasimovskaya $\mathrm{EV}, \mathrm{Li} \mathrm{M}$, et al. The adventitia: essential regulator of vascular wall structure and function. Annu Rev Physiol. (2013) 75:23-47. doi: 10.1146/annurev-physiol-030212-183802

37. Majesky MW, Horita H, Ostriker A, Lu S, Regan JN, Bagchi A, et al. Differentiated smooth muscle cells generate a subpopulation of resident vascular progenitor cells in the adventitia regulated by Klf4. Circ Res. (2017) 120:296-311. doi: 10.1161/CIRCRESAHA.116.309322

38. Houtkamp MA, de Boer OJ, van der Loos CM, van der Wal AC, Becker AE. Adventitial infiltrates associated with advanced atherosclerotic plaques: structural organization suggests generation of local humoral immune responses. J Pathol. (2001) 193:263-9. doi: 10.1002/10969896(2000)9999:9999<::AID-PATH774>3.0.CO;2-N

39. Lohoefer F, Reeps C, Lipp C, Rudelius M, Zimmermann A, Ockert $\mathrm{S}$, et al. Histopathological analysis of cellular localization of cathepsins in abdominal aortic aneurysm wall. Int J Exp Pathol. (2012) 93:252-8. doi: 10.1111/j.1365-2613.2012.00819.x

40. Akhavanpoor M, Gleissner CA, Akhavanpoor H, Lasitschka F, Doesch AO, Katus HA, et al. Adventitial tertiary lymphoid organ classification in human atherosclerosis. Cardiovasc Pathol. (2018) 32:8-14. doi: 10.1016/j.carpath.2017.08.002

41. Moos MP, John N, Grabner R, Nossmann S, Gunther B, Vollandt R, et al. The lamina adventitia is the major site of immune cell accumulation in standard chow-fed apolipoprotein E-deficient mice. Arterioscler Thromb Vasc Biol. (2005) 25:2386-91. doi: 10.1161/01.ATV.0000187470.31662.fe
42. Mohanta SK, Yin C, Peng L, Srikakulapu P, Bontha V, Hu D, et al. Artery tertiary lymphoid organs contribute to innate and adaptive immune responses in advanced mouse atherosclerosis. Circ Res. (2014) 114:1772-87. doi: 10.1161/CIRCRESAHA.114.301137

43. Buettner M, Lochner M. Development and function of secondary and tertiary lymphoid organs in the small intestine and the colon. Front Immunol. (2016) 7:342. doi: 10.3389/fimmu.2016.00342

44. Hwang JY, Randall TD, Silva-Sanchez A. Inducible bronchus-associated lymphoid tissue: taming inflammation in the lung. Front Immunol. (2016) 7:258. doi: 10.3389/fimmu.2016.00258

45. Srikakulapu P, Hu D, Yin C, Mohanta SK, Bontha SV, Peng L, et al. Artery tertiary lymphoid organs control multilayered territorialized atherosclerosis B-cell responses in aged ApoE $\mathrm{E}^{--/--}$mice. Arterioscler Thromb Vasc Biol. (2016) 36:1174-85. doi: 10.1161/ATVBAHA.115.306983

46. Hiraoka N, Ino Y, Yamazaki-Itoh R. Tertiary lymphoid organs in cancer tissues. Front Immunol. (2016) 7:244. doi: 10.3389/fimmu.2016.00244

47. Sautes-Fridman C, Lawand M, Giraldo NA, Kaplon H, Germain C, Fridman $\mathrm{WH}$, et al. Tertiary lymphoid structures in cancers: prognostic value, regulation, and manipulation for therapeutic intervention. Front Immunol. (2016) 7:407. doi: 10.3389/fimmu.2016.00407

48. van de Pavert SA, Mebius RE. New insights into the development of lymphoid tissues. Nat Rev Immunol. (2010) 10:664-74. doi: 10.1038/nri2832

49. Mebius RE. Organogenesis of lymphoid tissues. Nat Rev Immunol. (2003) 3:292-303. doi: 10.1038/nri1054

50. Barone F, Gardner DH, Nayar S, Steinthal N, Buckley CD, Luther SA. Stromal fibroblasts in tertiary lymphoid structures: a novel target in chronic inflammation. Front Immunol. (2016) 7:477. doi: 10.3389/fimmu.2016. 00477

51. Scandella E, Bolinger B, Lattmann E, Miller S, Favre S, Littman DR, et al. Restoration of lymphoid organ integrity through the interaction of lymphoid tissue-inducer cells with stroma of the T cell zone. Nat Immunol. (2008) 9:667-75. doi: 10.1038/ni.1605

52. Grandoch M, Feldmann K, Gothert JR, Dick LS, Homann S, Klatt $\mathrm{C}$, et al. Deficiency in lymphotoxin beta receptor protects from atherosclerosis in apoE-deficient mice. Circ Res. (2015) 116:e57-68. doi: 10.1161/CIRCRESAHA.116.305723

53. Guedj K, Khallou-Laschet J, Clement M, Morvan M, Gaston AT, Fornasa G, et al. M1 macrophages act as LTbetaR-independent lymphoid tissue inducer cells during atherosclerosis-related lymphoid neogenesis. Cardiovascular research. (2014) 101:434-43. doi: 10.1093/cvr/ cvt263

Conflict of Interest Statement: The authors declare that the research was conducted in the absence of any commercial or financial relationships that could be construed as a potential conflict of interest.

Copyright (c) $2019 \mathrm{Hu}$, Yin, Luo, Habenicht and Mohanta. This is an open-access article distributed under the terms of the Creative Commons Attribution License (CC $B Y)$. The use, distribution or reproduction in other forums is permitted, provided the original author(s) and the copyright owner(s) are credited and that the original publication in this journal is cited, in accordance with accepted academic practice. No use, distribution or reproduction is permitted which does not comply with these terms. 